\title{
A Review on Possible Increment of Heat Transfer Rate for Hydraulic Oil Used in Plastic Injection Moulding Machine
}

\author{
Sandip Kumar Das ${ }^{1}$, Kedar Bhojak ${ }^{2}$ \\ ${ }^{1}$ PG Student, Mechanical Engineering Department, L.D.R.P-I.T.R (KSV), Gandhinagar, Gujarat, India \\ ${ }^{2}$ Professor, Mechanical Engineering Department, L.D.R.P-I.T.R (KSV), Gandhinagar, Gujarat, India
}

\begin{abstract}
In present study, the effect of oil temperature of the hydraulic system for Plastic Injection Moulding Machine is studied. Traditionally, in India, the hydraulic oil VG-68 for Plastic Injection Moulding Machine is used, which has an optimum temperature range with desired effective viscosity property in between $40^{\circ} \mathrm{C}$ to $50^{\circ} \mathrm{C}$. The oil temperature goes higher up to $55^{\circ} \mathrm{C}$ and even higher than that during the summer, which is not desirable for the machine operations. It is found that the operation of the machine gets sluggish as the oil viscosity get decreases due to continuous flow and heavy production schedule. The oil needs to be cooled down as fast as possible from the elevated temperature to required temperature. The problem was initially solved by use of a heat exchanger which turned out to be a costly affair. The alternative method for getting the temperature drop up to the desired level is extended surface heat transfer through the flow of oil in the return path. The method is prominently permissive for elimination of the expensive heat exchanger usage. This paper critically examines the feasibility of such alternative methods on the basis of reported work of the past with similitude.
\end{abstract}

Keywords: Hydraulic system, VG-68, Plastic Injection Moulding Machine, Viscosity Grade oil, Heat Transfer Rate Increments, Heat Sink

\section{Introduction}

At present, the main focus of all the manufacturers is to manufacture the products in an optimised way with least cost of production. Keeping this factor in mind, most of the industrialist adapted plastic to replace the metal in the manufacturing process. This modification turns into the huge demand for the plastic processing machines. In markets, although, electrical injection moulding machines are available for the production, the hydraulic machines are more preferred due to their less initial cost and ease of maintenance. In practical manufacturing processes, the actual operating cost of the machine is much higher than the theoretical costs. The actual operating cost of production can be determined more precisely by considering critical factors, i.e., type of material used for plastic processing, hydraulic circuit design, mechanical design, tonnage requirements, etc. One of the most important parameter used in determining the actual operating cost is the viscosity of the hydraulic oil. Effectiveness of the overall system is dependent on the retention of the viscosity over the temperature range and is the major challenge for researchers. On the basis of viscosity, the selection of the adequate hydraulic oil has critical role which depends upon the conditions and the requirements of the system. To select the appropriate VG oil, having a desired viscosity at a known temperature, a graph [13] can be referred as shown in Fig. 1. From the past literature and survey, it is seen that in India or the Asian countries, VG-68 oil, is most suitable amongst all for hydraulic system for plastic injection moulding machine. The properties[14] of various viscosity grade oil and comparison between them is listed in a Table 1, as mentioned below.

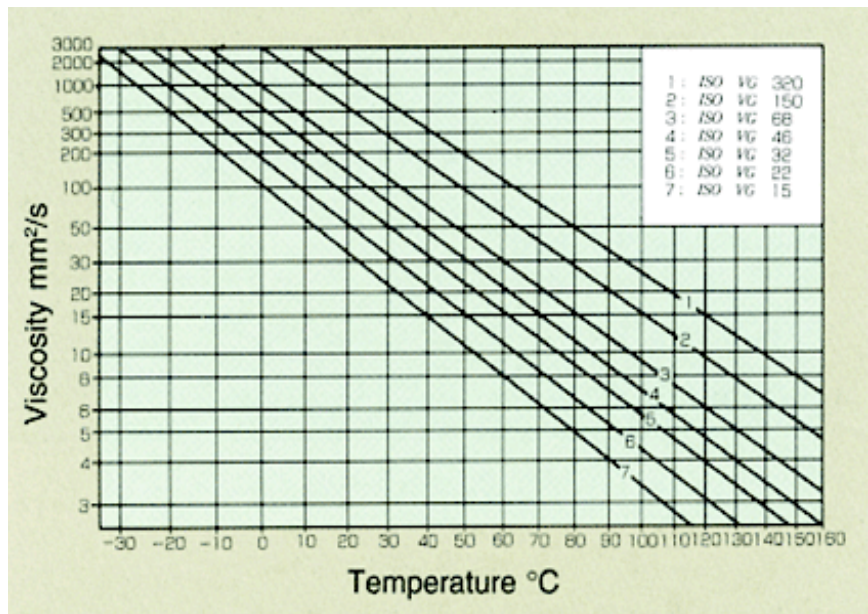

Figure 1: Viscosity versus Temperature [13]

\section{Hydraulic Oil Overheating}

It is found that VG-68 has an optimum operating temperature range between $40^{\circ} \mathrm{C}$ to $50^{\circ} \mathrm{C}$, but due the high productivity requirements, poor quality plastic resins selection for finished product and due to use of less effective heat exchangers in Plastic IMM particularly in India during summer, as mentioned earlier VG-68 oil temperature reaches above $55^{\circ} \mathrm{C}$, which is not desirable for machine operations.

Table 1: Properties and comparison of hydraulic oils

\begin{tabular}{|c|c|c|c|c|c|}
\hline Properties & Unit & & & & \\
\hline ISO Viscosity Grade & - & 22 & 32 & 46 & 68 \\
\hline Absolute Density, $15^{\circ} \mathrm{C}$ & $\mathrm{kg} / \mathrm{m}^{3}$ & 863 & 870 & 874 & 880 \\
\hline Kinematic Viscosity, $40^{\circ} \mathrm{C}$ & $\mathrm{mm}^{2} / \mathrm{s}$ & 22 & 32 & 46 & 68 \\
\hline Kinematic Viscosity, $100{ }^{\circ} \mathrm{C}$ & $\mathrm{mm}^{2} / \mathrm{s}$ & 4.28 & 5.33 & 6.72 & 8.66 \\
\hline Viscosity Index & - & 98 & 98 & 98 & 97 \\
\hline Flash Point & ${ }^{\circ} \mathrm{C}$ & 202 & 208 & 222 & 246 \\
\hline Pour Point & ${ }^{\circ} \mathrm{C}$ & -30 & -30 & -30 & -30 \\
\hline
\end{tabular}




\section{International Journal of Science and Research (IJSR) \\ ISSN (Online): 2319-7064 \\ Index Copernicus Value (2013): 6.14 | Impact Factor (2015): 6.391}

Hassani et al. [01] concluded that the hydraulic oil, which passes through any orifice produces heat. The factor which produces heat are pressure valves, relief valves, pipes with small diameters, dirty filters, internal leakage in the hydraulic system and friction. The hydraulic system in Plastic Injection Moulding Machine consists of circuits to accomplish various task in cylinders like mould clamp cylinder, retraction cylinder, injection cylinder, auxiliary cylinder etc[16]. Every of these circuits cause temperature rise because of pressure drop due to the resistance of the circuit comprising ingredients against fluid flow, the existence of throats (contracting) on the fluid passage and so on while the hydraulic system is working. Since the mentioned circuits have a common pump and reservoir, therefore the heat production in either circuit will affect other ones.The areas of heat generation in plastic injection moulding machine can be easily understood by generating a fishbone diagram, where bones are indicating the causes of heat generation.

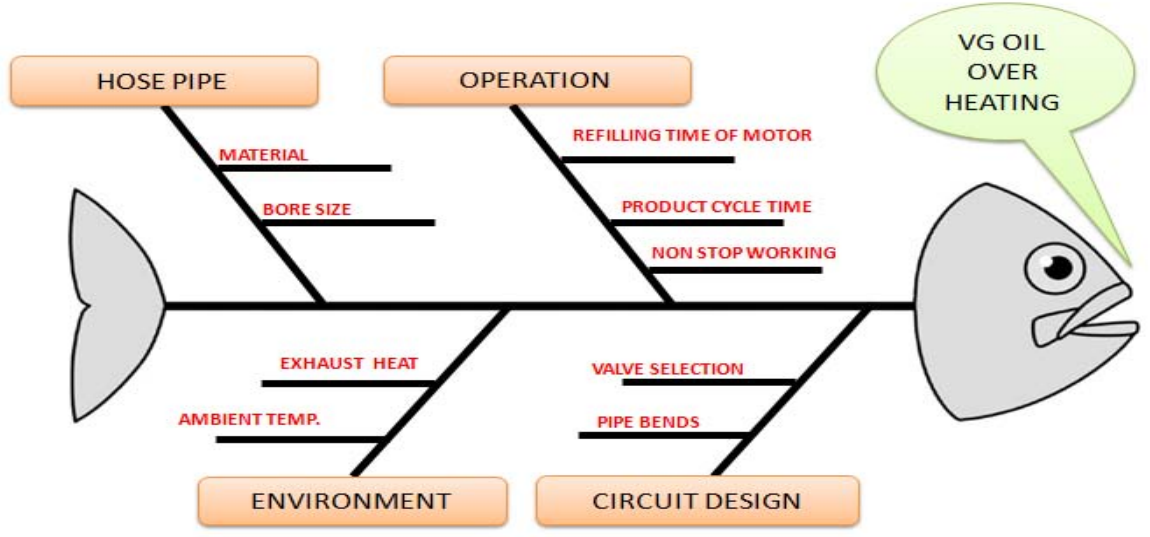

Figure 2: Fishbone diagram illustrating the causes of heat genration of hydraulic oil in IMM

To get better idea about the problem some machine are investigated, which are having 24 hours of working load condition and results are enlisted into a Table 2.

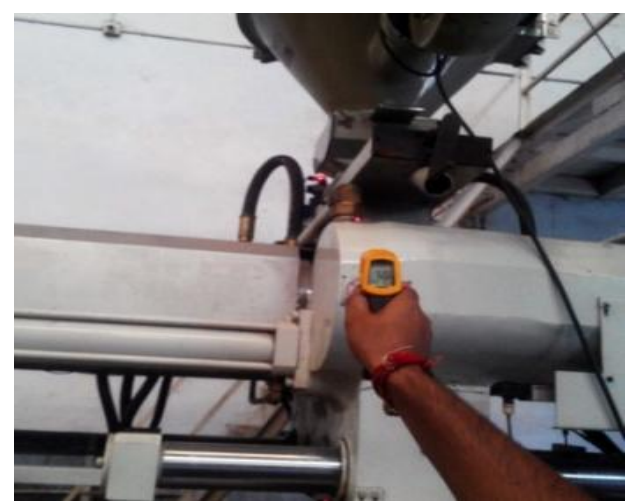

Figure 3: Reading on injection cylinder inlet/outlet port
From the experiments, when the ambient temperature was $39^{\circ} \mathrm{C}$, it is founded that some oil passage ports of hydraulic system of Plastic IMM are having temperature of $50^{\circ} \mathrm{C}$ and above. So it is clearly understood that during summer when ambient temperature reaches above $45^{\circ} \mathrm{C}$, the VG-68 oil temperature will be higher than $55^{\circ} \mathrm{C}$. From the Table 2, it is concluded that pump and the thrust unit of the Plastic Injection Moulding Machine are generating the most of the heat. So it is important to reject heat from those areas as much possible to make the system more effective.

Table 2: Experimental readings of Plastic IMM

TEMPERATURE READING $\left({ }^{\circ} \mathrm{C}\right.$ )

\begin{tabular}{|c|c|c|c|c|c|c|c|c|c|}
\hline \multicolumn{10}{|c|}{ TEMPERATURE READING ( ${ }^{\circ} \mathbf{C}$ ) } \\
\hline S.NO. & Machine & Pump & Clamp Cylinder & Ejector & Injection Cylinder & Retraction Cylinder & Thrust Unit & Oil Tank & Water \\
\hline $\mathbf{1}$ & HMT-220T & 43 & 41.5 & 40 & 43 & 43 & 42.5 & 40 & 30 \\
\hline $\mathbf{2}$ & JSW-220 & 50.5 & 48.5 & 39.5 & 44 & 47 & 51 & 51 & 32 \\
\hline $\mathbf{3}$ & SPRINT-650 & 51 & 48.5 & 37.5 & 48 & 49 & 50 & 47.8 & 30 \\
\hline
\end{tabular}

\section{Nomenclature}

VG: Viscosity Grade

IMM : Injection moulding machine

h: Coefficient of heat transfer

Tळ: Fluid surrounding temperature

FEA: Finite element analysis

FEM: Finite element method

Q: Heat Transfer rate

ISO; International organization for standardization

BG: Bond Graph

${ }^{\circ} \mathrm{C}$ : Degree Centigrade

m: Meter

$\mathrm{mm}$ : Millimetre

\section{Methods of Heat Transfer Increment}

To maintain the oil temperature within $50^{\circ} \mathrm{C}$, heat exchangers should not be the only option. It is desirable to find out the ways to maintain the VG-68 oil temperature within $55^{\circ} \mathrm{C}$ without affecting the cost, the following survey is required for the above mentioned problem.

Simulation of the hydraulic system is essential to find out the heat generation value. However there are lots of 


\section{International Journal of Science and Research (IJSR) \\ ISSN (Online): 2319-7064 \\ Index Copernicus Value (2013): 6.14 | Impact Factor (2015): 6.391}

researches are done by using FEA \& FEM simulation method but for the large hydraulic system, it is always difficult to find out the exact heat generation value and temperature rise. TOMIOKA et al. [02]states that to predict the temperature rise of the system, it is important to find out the simple and precise method. Author used Bond graph and Finite Element Method to conclude a coupled BG and FEM method, which will useful to simulate the hydraulic system. When the total heat generation is known, the amount of heat transfer rate increment for the system would not be difficult. It is mentioned that heat transfer can be increased by three means[06], where first is to increase hbut that require the installation of a fan or a pump. Second is to reduce $T_{\infty}$, which is often impractical and third is to increase surface area across the which the convection will take place. Another author Kreith F. et al.[17] revised the basics into more technical words and he states that the techniques for increasing the heat transfer rate can be divided in three categories. First is passive the method in which twisted tapes, helical screw tape inserts, rough surfaces, extended surfaces, additives for liquid and gases. The second is active method that requires external power like mechanical aids, surface fluid vibration, and use of electrostatic fields. Passive methods are found more inexpensive as compared to other group. The third is combined application of active and passive techniques to obtain enhancement in heat transfer that is greater than that produced by either of them when used individually, is termed as compound enhancement.

It was concluded by Hassani et al. [01] that in order to optimize the system it would not be essential to mount an oil cooler. From authores experiments it is found that steel pipe instead of non-metallic coated hoses are much better for heat transfer and enough to reject much of the heat generated in the system. Meganathan et al. [04]took a performance test of heat exchanger by using twisted tape and he found that heat transfer increase compare to the heat exchanger without twisted tape, he also states that the length of pipe is directly proportional to heat transfer (Q), when the length of fluid flow increases, heat transfer rate also increases [04], [06]. The experiment result of heat transfer rate for different length of pipes by author [04] is shown in fig.4.

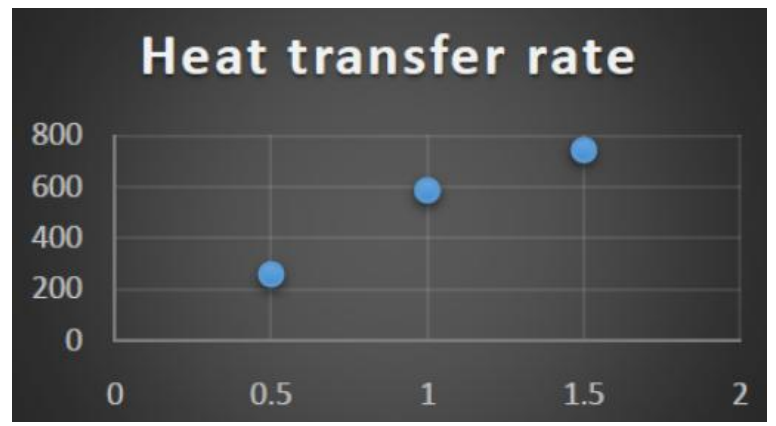

Figure 4: Length of pipe in (m) vs. Heat transfer rate (Q) [04]

Along with length of pipe, internal diameter and external diameter a pipe also plays an important role in effecting the heat transfer rate. The local Nusselt number is increased when Gül et al. [10]increases oscillating frequency. The experimental oscillating generator is not only efficient to enhance the heat transfer in the duct flow but also in a significant pressure drop increase. The exergy loss is decreased with the increase of Reynolds number however exergy loss is affected slightly from the increase of oscillating frequencies. Such type of research is done by lots of researchers [17], [18], [19],[20]and [04] where the researchers used the passive method by inserting twisted tape, screw tape because according tothe recent studies, these are known to be economictool in the field of heat transfer increment. Dewan et al. [19]has reviewed Techniques of heat transfer augmentation such as passive, active and combination of passive and active methods. Heat transfer rate increment in a pipe flow by inserts such as twisted tapes, ribs, wire coils and dimples is mainly due to flow blockage, partitioning of the flow and secondary flow. Manglik et al [20] used twisted tape induced helical swirl flows for enhancement of forced convective heat transfer in single phase and two phase flows. The author presented the heat transfer coefficient and friction factor correlations for both laminar and turbulent regimes, and also highlighted the damping effect of swirl on the transition region. Chowdhuri et al. [21]used a special geometry inside the tube for turbulent flow. The test section of tube is electrically heated, and then the air is allowed to flow as the working fluid through the tube by means of blowers. Same experiment is carried out to determine heat transfer through the same tube without any insert. Comparing the results obtained from these two different sets of experiments, author has found that heat transfer through tubes can be enhanced by using inserts inside the tube up to 9.8 times than tube without insert with turbulent flow.Totala et al.[26]conducted experiments by providing threads in the inner pipe and observed that Nusselt number and heat transfer coefficient were increased for the threaded pipe but at the same time pumping power required also increased compared to the plain tube. These are economical tool for heat transfer increment but pressure drop is noticed which of course is not desirable for inlet ports of hydraulic system of plastic injection moulding machine. For the outlet ports and return channel to the oil reservoir the method is suitable where the pressure drop is not so important.

Another option is to apply the fins over the pipes of the pipeline of the hydraulic system. The use of fin (extended surface) with extensions, provide efficient heat transfer [05],[06], [22], [23], [24], [25],Singh et al. [05]concludes 5 $\%$ to $13 \%$ more enhancement of heat transfer, when fin with extensions provided as compare to fin without extensions. From the experiments of Author on different shapes of fin extension, it is concluded that rectangular extension has the higher heat transfer as compared to others. Effectiveness of the rectangular fin extension is higher.A comparison table is generated by the author [05], which helps to decide the shape of extension for the fin. 


\section{International Journal of Science and Research (IJSR) \\ ISSN (Online): 2319-7064 \\ Index Copernicus Value (2013): 6.14 | Impact Factor (2015): 6.391}

Table 3: shows that comparison of temperatures of fin with different types of extensions corresponding to the length of fin [05]

\begin{tabular}{|c|c|c|c|c|c|}
\hline \multirow{2}{*}{$\begin{array}{c}\text { Length of fin } \\
\text { (mm) }\end{array}$} & \multicolumn{5}{|c|}{ Fin with different types of extensions (Temp. in ${ }^{\circ} \mathrm{C}$ ) } \\
\cline { 2 - 6 } & Rectangular & Trapezium & Triangular & Circular & No Extensions \\
\hline $\mathbf{5}$ & 53.90396 & 53.94466 & 53.93874 & 53.9446 & 53.91441 \\
\hline $\mathbf{1 0}$ & 53.53861 & 53.59288 & 53.58499 & 53.5928 & 53.55255 \\
\hline $\mathbf{1 5}$ & 53.17327 & 53.2411 & 53.23124 & 53.241 & 53.19069 \\
\hline $\mathbf{2 0}$ & 52.80792 & 52.88932 & 52.87748 & 52.8892 & 52.82883 \\
\hline $\mathbf{2 5}$ & 52.44257 & 52.53754 & 52.52373 & 52.5374 & 52.46696 \\
\hline $\mathbf{3 0}$ & 52.07723 & 52.18576 & 52.16998 & 52.18561 & 52.1051 \\
\hline $\mathbf{3 5}$ & 51.71188 & 51.83398 & 51.81623 & 51.83381 & 51.74324 \\
\hline $\mathbf{4 0}$ & 51.34654 & 51.4822 & 51.46247 & 51.48201 & 51.38138 \\
\hline
\end{tabular}

Thermal Analysis on Spiral fins of heat pipe module shows the maximum amount of heat transfer rate. Wankhede et al.[03]used piping with spiral fins on it and checked the results by changing the flow rates of oil through it, where he found that overall heat transfer coefficient increases with the increase in mass flow rate. Analysis result is shown in fig. 5.

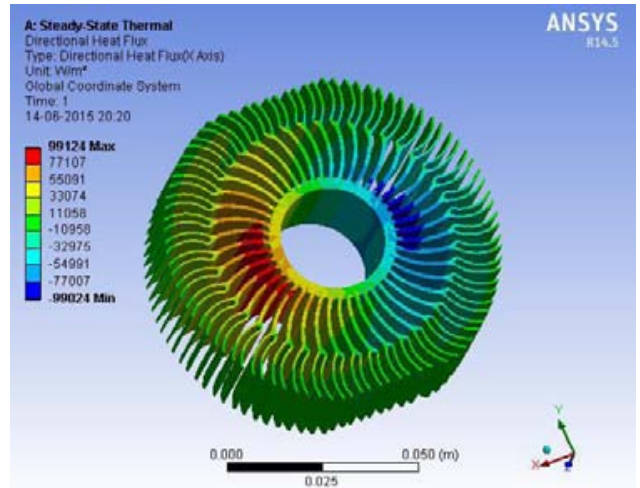

Figure 5: Rate of Heat flux Transfer through Fins [03]

Khannan et al. [27] studied three different configurations on the outside surface of the outer tube of annular ring, spiral rod and rectangular projection. It was observed by varying mass flow rates that the heat transfer rate was increased for a finned tube and fin with annular ring showed better performance than other methods.

\section{Conclusion and Future Task}

For the Indian hot conditions, when the ambient temperature will rise up to $45^{\circ} \mathrm{C}$, and the Injection moulding machines operating with heavy load, the oil temperature will rise about $55^{\circ} \mathrm{C}$ and above and that is not desirable for the machine operation as there will be viscosity retention problem and the proper viscosity is vital for the machine operation. Passive methods for increasing heat transfer rate for hydraulic oil looks promisive, but inserts for pipe has limitation of installation in the machine, due to huge pressure drop. Pipe with surface area extension will be a good choice to increase heat transfer rate. The scope of this review for heat transfer increment is the implementation of techniques on the machine wherever it is possible and find out the results of applicability. However these techniques are also applicable to other applications of machine, whichever is powered by hydraulic oil.

\section{Acknowledgement}

The research is supported by the L.D.R.P-ITR, Inflibnet and Windsor machines ltd, to acquire enough information about the Plastic Injection Moulding machine, hydraulic system and the Thermal science related to it.

\section{References}

[1] Hassani, H. S., Jafari, A., Mohtasebi, S. S., \&Setayesh, A. M. (2010). Transient heat transfer analysis of hydraulic system for JD 955 harvester combine by finite element method. Journal of Food, Agriculture \& Environment, 8(2), 382-385.

[2] TOMIOKA, K., TANAKA, K., NAGAYAMA, K., \& TOKUDA, K. (2005). Simulation Model of Heat Generation and Transfer in Oil-Hydraulic System. In Proceedings of the JFPS International Symposium on Fluid Power (Vol. 2005, No. 6, pp. 120-125). The Japan Fluid Power System Society.

[3] Ashish., Wankhede, et al. (2015). Design and Analysis of Hydraulic Oil Cooler by Application of Heat Pipe. In International Journal of Science, Engineering and Technology Research (IJSETR), 3190-3193.

[4] Meganathan, B. et al. (2015). Experimental Investigation of Heat Transfer Using „Twisted Aluminium Tape ${ }^{e e}$. In Int. Journal of Engineering Research and Applications, 1-4.

[5] Singh, P. (2014). Harvinderlal, Baljit Singh Ubhi, Design and analysis for heat transfer through fin with extensions. International Journal of Innovative Research in Science, Engineering and Technology (An ISO 3297: 2007 Certified Organisation) Vol, 3.

[6] Nag, P. K. (2006). Heat \& Mass Transfer. Tata McGraw Hill Co. Pg, (1-157), 425-449.

[7] "Hydraulic Systems" NPTEL - Mechanical Mechatronics and Manufacturing Automation -Web course.

[8] Thyregod, P., Spliid, H., Melgaard, H., \& Madsen, H. (2001). Modelling and monitoring in injection molding (Doctoral dissertation, Technical University of DenmarkDanmarksTekniskeUniversitet, AdministrationAdministration, Office for Study Programmes and Student AffairsAfdelingen for UddannelseogStuderende).

[9] Dominick, V. R., \& Donald, V. R. (2000). Injection molding handbook. Kluwer Academic Publishers, Boston, 110, 697. 


\section{International Journal of Science and Research (IJSR) \\ ISSN (Online): 2319-7064 \\ Index Copernicus Value (2013): 6.14 | Impact Factor (2015): 6.391}

[10] Gül, H., \&Akpinar, E. K. (2007). Investigation of heat transfer and exergy loss in oscillating circular pipes. International communications in heat and mass transfer, 34(1), 93-102.

[11] Deborah Hays (2008). Reducing Hydraulic System Temperatures. In Inframation.

[12] Bruce I. Nelson, P.E., President. "THE ALUMINUM ADVANTAGE" Comparing Aluminum v Galvanized Steel Ammonia Evaporators.

[13] http://www.ntn.co.jp/english/products/care/check/ [Accessed: December 29,2015]

[14] http://www.oils.am/home/157.html

[Accessed: December 23,2015]

[15] http://injectionmoldingmachine.tayu.cn/injectionmachine/205.html [Accessed: December 25, 2015]

[16] Rosato, D. V., \&Rosato, M. G. (2012). Injection molding handbook. Springer Science \& Business Media.

[17] Kreith F., Timmerhaus K., Lior N., Shaw H., Shah R.K., Bell K. J.,etal.."Applications.” The CRC Handbook of Thermal Engineering. Ed. Frank Kreith. Arthur E. Bergles. Boca Raton: CRC Press LLC, 2000, 408-457.

[18] Patil, S. V., \&Babu, P. V. (2011). Heat Transfer Augmentation in a Circular tube and Squareduct Fitted with Swirl Flow Generators: A Review. International Journal of Chemical Engineering and Applications, 2(5), 326.

[19] Dewan, A., Mahanta, P., Raju, K. S., \& Kumar, P. S. (2004). Review of passive heat transfer augmentation techniques. Proceedings of the Institution of Mechanical Engineers, Part A: Journal of Power and Energy, 218(7), 509-527.

[20] Manglik, R. M., \&Bergles, A. E. (2013). Characterization of twisted-tape-induced helical swirl flows for enhancement of forced convective heat transfer in single-phase and two-phase flows. Journal of Thermal Science and Engineering Applications, 5(2), 021010.

[21] Chowdhuri, M. A. K., Hossain, R. A., \& Sarkar, M. A. R. (2011). An experimental investigation of turbulent flow heat transfer through tube with rod-pin insert. International Journal of Engineering, Science and Technology, 3(4).

[22] Mon, M. S., \& Gross, U. (2004). Numerical study of fin-spacing effects in annular-finned tube heat exchangers. International Journal of Heat and Mass Transfer, 47(8), 1953-1964.

[23] Kundu, B., \& Das, P. K. (2002). Performance analysis and optimization of straight taper fins with variable heat transfer coefficient. International journal of heat and mass transfer, 45(24), 4739-4751.

[24] Kadam, D. (2012). Performance simulation of fin and tube heat exchanger. International journal of educational science and research, 2(10).

[25] Antony, A. \&Ganesan, M. (2014). Flow analysis and characteristics comparison of double pipe heat exchanger using enhanced tubes. Journal of Mechanical and Civil Engineering, 7: 16-21.

[26] Totala, N. \& Desai, V. et al. (2014). Manufacturing and comparative analysis of threaded tube heat exchanger with straight tube heat exchanger. International Journal of Engineering and Science, 4(7): 77-85.
[27] Kannan, M., Ramu, S., Santhanakrishnan, S. \&Arunkumar, G. (2012). Vivek. M "experimental and analytical comparison of heat transfer in double pipe heat exchanger," International Journal of Mechanical Engineering applications Research-IJMEAR, 3(03), 170-174.

[28] http://windsormachines.com/injection-mouldingmachines.htm[Accessed: December 25, 2015]

\section{Author Profile}

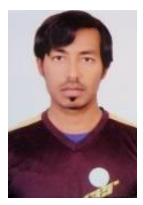

Sandip Kumar Das received the B.E. degree inMechanical Engineering from Universal College of Engineering and Technology in 2013. He pursuing M.E. in Thermal engineering at L.D.R.PInstitute of Technology and research 2014-2016. And he is doing his project work on "Analysis and Enhancement of oil recirculation system for Plastic Injection Moulding Machine" at Windsor Machines Limited. 